\title{
Investigating personal characteristics of entrepreneurs
}

\author{
Ahmad Ahmadkhani ${ }^{a^{*}}$, Leyla Heydari ${ }^{a}$, Maryam Heydari ${ }^{a}$ and Gholam Panahandeh ${ }^{b}$
}

${ }^{a}$ Young Researchers and EliteClub, Zanjan Branch, Islamic Azad University, Zanjan, Iran

${ }^{b}$ Master in Management, Science and Research Branch, Islamic Azad University, Tehran, Iran

\section{CHRON I C L E}

\section{Article history:}

Received May 16, 2013

Received in revised format

16 August 2013

Accepted 28 September 2013

Available online

October 42013

Keywords:

Entrepreneurs

Personal characteristics

Islamic Azad University of Zanjan

\section{A B S T R A C T}

Personal characteristics of an entrepreneur are always considered as the most important parameters on creating jobs and opportunities, successfully. This paper presents an empirical study on personal characteristics of students who are supposed to act as entrepreneur to create jobs in two major fields of engineering and social sciences at Islamic Azad University located in city of Zanjan, Iran. There are eight aspects of accepting reasonable risk, locus of control, the need for success, mental health conditions, being pragmatic, tolerating ambiguity, dreaming and the sense of challenging in our study to measure the level of entrepreneurship. We uniformly distribute 366 questionnaires among undergraduate students in two groups and analyze the results based on t-student test. The results confirmed that the students who were enrolled in social sciences accept a reasonable amount of risk, maintain sufficient locus of control, wish to reach prosperity and success in their carrier and lives and maintain a good level of dreaming. On the other hand, the students who were enrolled in engineering field have sufficient level of mental health care, they are pragmatic and are able to handle ambiguity and they can handle possible challenges in their jobs, properly.

(C) 2013 Growing Science Ltd. All rights reserved.

\section{Introduction}

Nowadays, people with great personality are considered as the best candidates of being successful entrepreneurs in various fields such as information technology, retail industries, etc. There are some dedicated people like Steve Jobs, who contributed all their lives to create value added products. These people leave a cultural heritage among our nations and teach some moral stories. There is a common feature among all these people, which is associated with their personal characteristics. People like Bill Gates spent all their personal times including their weekend to present a well-known product such as Windows operating system, which would help literally billions of people round the world (Ahmadkhani et al., 2012).

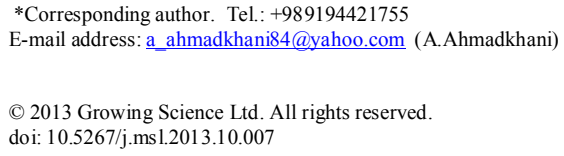


Personality is one of the characteristics of entrepreneurs and in any cases, this is the primary criterion to decide whether an entrepreneur is entitled to receive financial assistance or not. In fact, many banks' officials, venture capitals make their financing decisions solely based on the interview on entrepreneurs' personal characteristics. During the past few decades, there have been tremendous efforts on detecting important factors on the success of an entrepreneur (Ahmadkhani et al., 2012).

Khorshidifar and Abedi (2010) performed an empirical investigation on the effect of stress on the relationship between locus of control and job satisfaction and job performance. They selected a sample size of 65 senior and regular accountants who worked for thirteen various regional municipalities of city of Mashad located in east part of Iran and applied different well-known questionnaire techniques such as stress diagnostic survey, locus of control, job satisfaction and employees' performance to perform the study. They reported that the stress had been on average level for the dominant locos of control factors and job satisfaction and employee performance had been in relatively high level. The study also disclosed that there were four major factors of role of ambiguity, quantitative overload, career development and handling other workers' responsibilities played important role on job satisfaction and managing career development has important impact on the performance of accountants.

Nicholson (1998) studied the question of whether there was an entrepreneurial leadership personality profile applying an empirical investigation of the heads of the UK's top independent firms and compared them with sample norms and a management control group. Wijbenga and van Witteloostuijn (2007) investigated the effect of environmental dynamism on entrepreneurial locus of control-competitive strategy relationship and reported that internal entrepreneurs prefered product innovation strategies in stable environments, whereas external entrepreneurs opt for low-cost strategies in dynamic environments. Zampetakis (2008) investigated the role of creativity and proactivity on perceived entrepreneurial desirability. Zhou (2007) performed a comprehensive investigation on the impacts of entrepreneurial proclivity and foreign market knowledge on early internationalization. Brush et al. (2009) presented pathways to entrepreneurial growth by investigating the effect of management, marketing and money. They stated that fast-growing firms could exhibit various rates and patterns of growth: some represent fast growth trajectories; some, slower, more measured rates; others, episodic periods of quick growth followed by sharp retrenchment. They also found that three key factors - management, marketing, and money - affected company growth across these patterns. Obschonka et al. (2010) reported that entrepreneurial intention could be the key success for new ideas. Ucbasaran et al. (2010) performed an investigation on the nature of entrepreneurial experience, business failure and comparative optimism. Lin (2006) presented a comparative investigation on the trends of entrepreneurial behaviors of enterprises in different strategies. Schmitt-Rodermund (2004) introduced four characteristics of parenting, personality, early entrepreneurial competence, and interests for the success of entrepreneurship. She stated that an early start-up and an entrepreneurial personality of the founder could be considered as important factors.

In this paper, we present an empirical investigation to measure various entrepreneurship characteristics of students who were enrolled in two areas of engineering and social sciences. The study designs a questionnaire based on different criteria such as locus of control, need for success, dream, challenge, etc. The organization of this paper is as follows. We first present details of our questionnaire in section 2 and the results of our analysis are discussed in section 3. Finally, concluding remarks are given in the last to summarize the contribution of this paper.

\section{Problem statement}

In this paper, we select a sample size from all students who were enrolled in two different fields of engineering and social sciences at Islamic Azad University located in city of Zanjan, Iran. The sample size is calculated as follows, 
$n=\frac{N \times z_{\alpha / 2}^{2} \times p \times q}{\varepsilon^{2} \times(N-1)+z_{\alpha / 2}^{2} \times p \times q}$,

where $N$ is the population size, $p=1-q$ represents the yes/no categories, $z_{\alpha / 2}$ is CDF of normal distribution and finally $\varepsilon$ is the error term. Since we have $p=0.5, z_{\alpha / 2}=1.96, \varepsilon=0.03$ and $N=8000$, the number of sample size is calculated as $n=366$. The questionnaire was designed based on Likert scale (Likert, 1932) from completely agree to completely disagree in four different scales. Fig. 1 shows some of the personal characteristics of the participants.

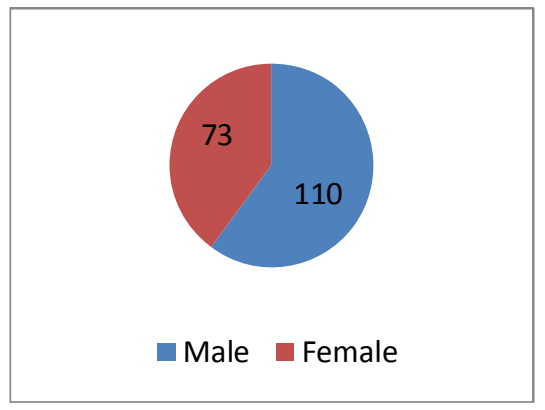

Gender

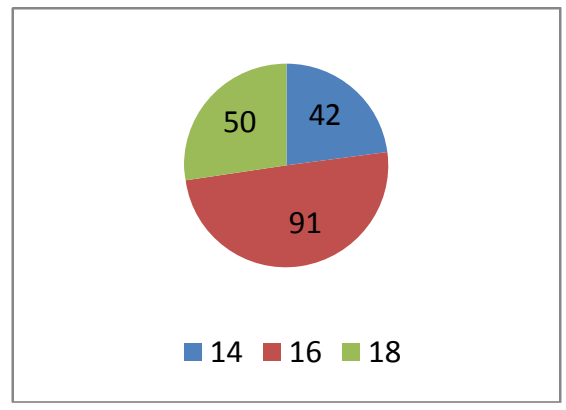

Years of education

Fig. 1. Personal characteristics of the participants

Note that, in our survey, we have selected equal numbers of people from two groups of engineering and social sciences in terms of gender and educational background. In addition, the participants were asked about their experiences and whether were interested in being entrepreneur or not and Fig 2. summarize the results of our survey.

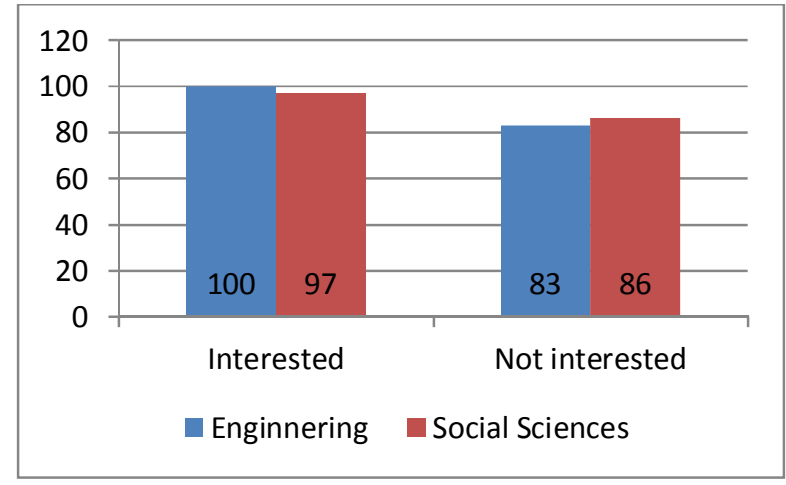

Interested in being entrepreneur

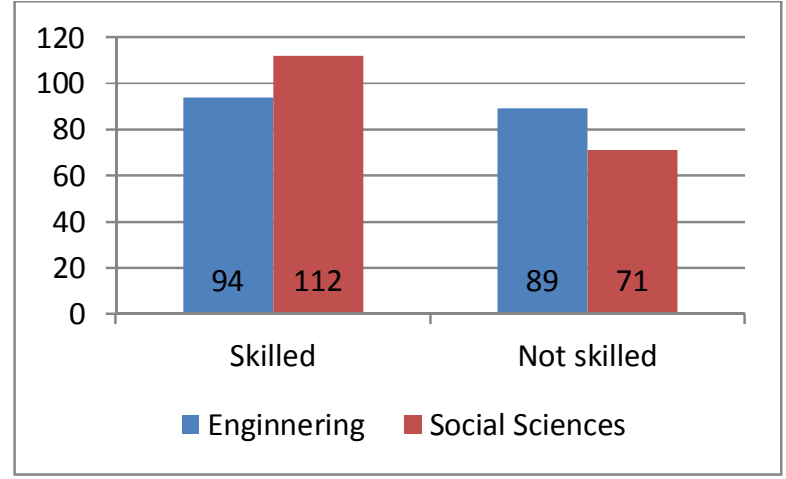

Having good skills

Fig. 2. Personal background

The proposed study of this paper considers the following eight hypotheses,

1. Students accept reasonable amount risk (ARR).

2. Students have desirable level of locus of control (LOC).

3. Students have desirable level of reaching prosperity and success (NFS).

4. Students are in good mental health conditions (MHC).

5. Students are pragmatic $(\mathrm{P})$.

6. Students could handle a good level of ambiguity (HA). 
7. Students have desirable level of dreaming (D).

8. Students could handle challenges in their life (C).

\section{Results}

In this section, we present details of our finding on eight hypotheses.

\subsection{Accepting desirable level of risk}

The first hypothesis is associated with the level of risk they could accept.

$\begin{cases}H_{0}: & \text { Students do not accept sufficient level of risk } \\ H_{1}: & \text { Students accept sufficient level of risk }\end{cases}$

Table 1 shows details of our finding,

Table 1

The results of t-student for ARR

\begin{tabular}{lcccccc}
\hline Group & t-student & df & Sig. (2-tailed) & Mean difference & Lower & Upper \\
\hline Social Science & 29.667 & 183 & 0.000 & 2.985 & 2.1833 & 2.4943 \\
Engineering & 27.989 & 183 & 0.591 & 3.123 & 1.9758 & 2.2755 \\
\hline
\end{tabular}

As we can observe from the results of Table 1, we have a meaningful level of t-student for those who were enrolled in social science but t-student is not significance for engineering students, which means we can reject the null hypothesis for those where enrolled in social sciences and accept alternative hypothesis. Therefore, we can conclude that the students graduated from the first group, social science, accept a reasonable amount of risk.

\subsection{Locus of control}

The second hypothesis is associated with the locus of control.

$\begin{cases}H_{0}: & \text { Students do not have desirable locus of control } \\ H_{1}: & \text { Students have desirable locus of control }\end{cases}$

Table 2 demonstrates details of our test,

Table 2

The results of t-student for LOC

\begin{tabular}{lcccccc}
\hline Group & t-student & df & Sig. (2-tailed) & Mean difference & Lower & Upper \\
\hline Social Science & 26.501 & 183 & 0.000 & 2.495 & 2.0989 & 2.4366 \\
Engineering & 26.613 & 183 & 0.674 & 3.245 & 2.0693 & 2.4007 \\
\hline
\end{tabular}

Again the results of Table 2 show that, we have a meaningful level of t-student for those who were enrolled in social science but t-student is not significance for engineering students, which means we can reject the null hypothesis for those where enrolled in social sciences and accept alternative hypothesis. Therefore, we can conclude that the students graduated from the first group, social science, maintain sufficient locus of control.

\subsection{Motivation of having prosperity and success}

The third hypothesis is associated with their wish to reach prosperity and success. 
$\left\{H_{0}\right.$ : Students do not have good motivation to reach prosperity and success

$H_{1}$ : Students wish to reach prosperity and success

Table 3 demonstrates details of our test,

Table 3

The results of $\mathrm{t}$-student for NFS

\begin{tabular}{lcccccc}
\hline Group & t-student & df & Sig. (2-tailed) & Mean difference & Lower & Upper \\
\hline Social Science & 36.292 & 183 & 0.000 & 2.245 & 2.0989 & 2.9730 \\
Engineering & 31.942 & 183 & 0.542 & 3.330 & 2.2664 & 2.5645 \\
\hline
\end{tabular}

Once more, the results of Table 3 indicate that, we have a meaningful level of t-student for those who were enrolled in social science but t-student is not significance for engineering students, which means we can reject the null hypothesis for those where enrolled in social sciences and accept alternative hypothesis. Therefore, we can conclude that the students graduated from the first group, social science, wish to reach prosperity and success in their carrier and lives.

\subsection{Having sufficient health care}

The fourth hypothesis is associated with their mental health care (MHC).

$\begin{cases}H_{0}: & \text { Students do not have good mental health care } \\ H_{1}: & \text { Students have good mental health care }\end{cases}$

Table 4 demonstrates details of our test,

\section{Table 4}

The results of t-student for MHC

\begin{tabular}{lcccccc}
\hline Group & t-student & df & Sig. (2-tailed) & Mean difference & Lower & Upper \\
\hline Social Science & 26.648 & 183 & 0.721 & 2.975 & 1.8823 & 2.1833 \\
Engineering & 26.504 & 183 & 0.000 & 2.375 & 1.8764 & 2.1782 \\
\hline
\end{tabular}

As we can observe from the results of Table 4, we have a meaningful level of t-student for those who were enrolled in engineering but t-student is not significance for social sciences students, which means we can reject the null hypothesis for those where enrolled in engineering and accept alternative hypothesis. Therefore, we can conclude that the students graduated from the second group, engineering, have sufficient level of mental health care.

\subsection{Being pragmatic}

The fifth hypothesis is associated with their sense of being pragmatic (P).

$\begin{cases}H_{0}: & \text { Students are not pragmatic } \\ H_{1}: & \text { Students are pragmatic }\end{cases}$

Table 5 demonstrates details of our test,

Table 5

The results of t-student for being pragmatic

\begin{tabular}{lcccccc}
\hline Group & t-student & df & Sig. (2-tailed) & Mean difference & Lower & Upper \\
\hline Social Science & 32.497 & 183 & 0.648 & 3.162 & 2.1249 & 2.3997 \\
Engineering & 32.238 & 183 & 0.000 & 2.251 & 2.1136 & 2.3892 \\
\hline
\end{tabular}


As we can observe from the results of Table 5, we have a meaningful level of t-student for those who were enrolled in engineering but t-student is not significance for social sciences students, which means we can reject the null hypothesis for those where enrolled in engineering and accept alternative hypothesis. Therefore, we can conclude that the students graduated from the second group, engineering, are pragmatic.

\subsection{Handling ambiguity}

The sixth hypothesis is associated with their sense of handling ambiguity (HA)

$\left\{H_{0}: \quad\right.$ Students are not able to handle ambiguity

$H_{1}$ : $\quad$ Students are able to handle a sufficient level of ambiguity

Table 6 demonstrates details of our test,

\section{Table 6}

The results of t-student for handling ambiguity

\begin{tabular}{lcccccc}
\hline Group & t-student & df & Sig. (2-tailed) & Mean difference & Lower & Upper \\
\hline Social Science & 29.056 & 183 & 0.641 & 2.851 & 2.1036 & 2.4101 \\
Engineering & 28.843 & 183 & 0.000 & 2.245 & 2.0923 & 2.3995 \\
\hline
\end{tabular}

One more, we can observe from the results of Table 6, we have a meaningful level of t-student for those who were enrolled in engineering but t-student is not significance for social sciences students, which means we can reject the null hypothesis for those where enrolled in engineering and accept alternative hypothesis. Therefore, we can conclude that the students graduated from the second group, engineering, are able to handle ambiguity.

\subsection{Dreaming}

The seventh hypothesis is associated with their sense of dreaming (D)

$\left\{H_{0}: \quad\right.$ Students do not have sufficient level of dreaming

$H_{1}: \quad$ Students have sufficient level of dreaming

Table 7 demonstrates details of our test,

Table 7

The results of $\mathrm{t}$-student for handling sufficient level of dreaming

\begin{tabular}{lcccccc}
\hline Group & t-student & df & Sig. (2-tailed) & Mean difference & Lower & Upper \\
\hline Social Science & 29.667 & 183 & 0.000 & 2.985 & 2.1833 & 2.4943 \\
Engineering & 27.989 & 183 & 0.591 & 3.123 & 1.9758 & 2.2755 \\
\hline
\end{tabular}

As we can observe from the results of Table 7, we have a meaningful level of t-student for those who were enrolled in social science but t-student is not significance for engineering students, which means we can reject the null hypothesis for those where enrolled in social sciences and accept alternative hypothesis. Therefore, we can conclude that the students graduated from the first group, social science, maintain a good level of dreaming.

\subsection{The Handling possible challenges $(C)$}

The eighth hypothesis is associated with their sense of handling possible challenges (C)

$\left\{H_{0}: \quad\right.$ Students cannot handle possible challenges with their jobs

$H_{1}: \quad$ Students can handle challenges with their jobs

Table 8 demonstrates details of our test, 
Table 8

The results of t-student for handling possible challenges

\begin{tabular}{lcccccc}
\hline Group & t-student & df & Sig. (2-tailed) & Mean difference & Lower & Upper \\
\hline Social Science & 27.018 & 183 & 0.672 & 3.817 & 1.9299 & 2.2340 \\
Engineering & 32.715 & 183 & 0.000 & 2.387 & 2.2440 & 2.5320 \\
\hline
\end{tabular}

As we can observe from the results of Table 5, we have a meaningful level of t-student for those who were enrolled in engineering but t-student is not significance for social sciences students, which means we can reject the null hypothesis for those where enrolled in engineering and accept alternative hypothesis. Therefore, we can conclude that the students graduated from the second group, engineering, can handle possible challenges in their jobs, properly.

\section{Conclusion}

In this paper, we have demonstrated an empirical study on personal characteristics of students who were enrolled in two different fields of engineering and social sciences. There were eight hypotheses with the proposed study of this paper including accepting reasonable risk, locus of control, the need for success, mental health conditions, being pragmatic, tolerating ambiguity, dreaming and the sense of challenging to measure the level of entrepreneurship. We have uniformly distributed 366 questionnaires among participants and analyzed the results based on t-student test. The results confirmed that the students who were enrolled in social sciences accept a reasonable amount of risk, maintain sufficient locus of control, wish to reach prosperity and success in their carrier and lives and maintain a good level of dreaming. On the other hand, the students who were enrolled in engineering field have sufficient level of mental health care, they are pragmatic and are able to handle ambiguity and they can handle possible challenges in their jobs, properly.

\section{Acknowledgment}

The authors would like to thank the anonymous referees for constructive comments on earlier version of this paper. This research has been supported by Young Researchers and EliteClub of Islamic Azad University of Zanjan Branch on a project entitled "Investigating personal characteristics of entrepreneurs in engineering and social sciences" and the authors would like to thank them for their financial support.

\section{References}

Ahmadkhani, A., Paknezhad, M., \& Nazari, A. (2012). An empirical study on entrepreneurs' personal characteristics. Management Science Letters, 2(3), 751-756.

Brush, C.G., Ceru, D.J., \& Blackburn, R. (2009). Pathways to entrepreneurial growth: The influence of management, marketing, and money. Business Horizons, 52(5), 481-491.

Cronbach, L. J. (1951). Coefficient alpha and the internal structure of tests. Psychometrika, 16(3), 297-334.

Friedman, M. (1940). A comparison of alternative tests of significance for the problem of $m$ rankings. The Annals of Mathematical Statistics, 11 (1), 86-92.

Khorshidifar, M., \& Abedi, A. (2010). An empirical study on the impact of stress on the relationship between locus of control and job satisfaction and job performance. Management Science Letters, 4(1), 511-516.

Likert, R. (1932). A Technique for the Measurement of Attitudes. Archives of Psychology, 140, 1-55.

Lin, W.B. (2006). A comparative study on the trends of entrepreneurial behaviors of enterprises in different strategies: Application of the social cognition theory. Expert Systems with Applications, $31(2), 207-220$. 
Nicholson, N. (1998). Personality and entrepreneurial leadership: A study of the heads of the UK's most successful independent companies. European Management Journal, 16(5), 529-539.

Obschonka, M., Silbereisen, R. K., Schmitt-Rodermund, E. (2010). Entrepreneurial intention as developmental outcome. Journal of Vocational Behavior, 77(1), 63-72.

Schmitt-Rodermund, E. (2004). Pathways to successful entrepreneurship: Parenting, personality, early entrepreneurial competence, and interests. Journal of Vocational Behavior, 65(3), 498-518.

Ucbasaran, D., Westhead, P., Wright, M., \& Flores, M. (2010). The nature of entrepreneurial experience, business failure and comparative optimism. Journal of Business Venturing, 25(6), 541555.

Wijbenga, F.H., \& van Witteloostuijn, A. (2007). Entrepreneurial locus of control and competitive strategies - The moderating effect of environmental dynamism. Journal of Economic Psychology, 28(5), 566-589.

Zampetakis, L.A. (2008). The role of creativity and proactivity on perceived entrepreneurial desirability. Thinking Skills and Creativity, 3(2), 154-162.

Zhou, L. (2007). The effects of entrepreneurial proclivity and foreign market knowledge on early internationalization. Journal of World Business, 42(3), 281-293. 